\title{
La política mexicana de inmigración en la época post-revolucionaria, 1920-1934
}

\section{Mónika Szente Varga}

Todos los gobiernos mexicanos de la primera mitad del siglo veinte estuvieron de acuerdo en la necesidad de aumentar la población nacional. Sin embargo, esto no implicó una continuidad en la política de inmigración, y es por tanto conveniente analizarla en períodos específicos, como el porfiriato, la revolución de 1910, la época post-revolucionaria, el cardenismo, la segunda guerra mundial y la postguerra. El objetivo principal de este estudio es definir en qué medida la política oficial de México se puede considerar como causa y promotor, o bien como resultado de la inmigración. Se eligió el período entre la revolución y el cardenismo -1920 a 1934- ya que en estos años se da tanto una activa legislación en materia de inmigración como una tasa muy alta de ingresos de extranjeros al país.

En la primera mitad de los años veinte la política gubernamental volvió a apoyar la inmigración, si bien con objetivos distintos de los del porfiriato, ${ }^{1}$ atendiéndose en esta etapa principalmente las razones de tipo económico:

- fomentar la economía nacional, que se encontraba en muy malas condiciones al término de la Revolución,

- atraer capital extranjero,

- mejorar las relaciones con el resto del mundo,

- ayudar al crecimiento de la población, que durante la Revolución sufrió un decremento de unas 800.000 personas $^{2}$

En los años veinte tanto Obregón como Calles pronunciaron discursos en los que promovían abiertamente la inmigración. ${ }^{3}$

[Tengo] una fe de fanático en que México es un país bastante rico para hacer felices a sus hijos, y no sólo para ellos, sino que nos pone en condiciones de abrir los brazos a los hermanos de otros países. Todos los extranjeros tienen en este país un amplio campo de acción. Los extranjeros pueden venir con la seguridad absoluta de que aquí encontrarán toda clase de afectos y atenciones siempre que vengan a desarrollar con nosotros una labor ecuánime, que no vengan a explotarnos, a llevarse nuestras riquezas, sin dejarnos nada, sino que vengan a cumplir y a respetar nuestras leyes y nuestras instituciones; en una palabra, que vengan a convivir con nosotros. ${ }^{4}$

Efectivamente, el número de llegadas empezó a crecer, pero es necesario reconocer que esto no fue directamente el fruto de esas políticas, sino principalmente la consecuencia del sistema de cuotas introducido en los Estados Unidos (1921 y 1924), que canalizó parte de la ola humana hacia México, desde donde los viajeros esperaban poderse adentrar en aquel país más fácilmente.

La Ley de Migración de 1926

\footnotetext{
${ }^{1}$ Durante el porfiriato una de las razones principales para apoyar la inmigración fue la idea de "blanquear" la población nacional.

${ }^{2}$ Sergio CAMPOSORTEGA CRUZ, "Análisis demográfico de las corrientes migratorias a México desde finales del siglo XIX", in: María Elena OTA MISHIMA (ed.), Destino México. Un estudio de las migraciones internacionales a México, siglos XIX y XX, México, El Colegio de México 1997, 30

${ }^{3}$ Para más detalles sobre las invitaciones a extranjeros y en particular, a judíos, véase: Gloria CARREÑO, "Pasaporte a la esperanza", in: Alicia GOJMAN DE BACKAL (ed.), Generaciones judías en México. La Kehilá Ashkenazi, 1922-1992, Tomo I, México, Comunidad Ashkenazí de México 1993, 49-57

${ }^{4} 26$ de febrero de 1926, discurso de Plutarco Elías Calles ante el Congreso Neolonés, Monterrey
} 
La creciente inmigración extranjera y la también creciente emigración de mexicanos, especialmente hacia los Estados Unidos, hicieron ineludible elaborar una nueva ley migratoria. En este ambiente nació la segunda ley de migración, publicada el 13 de marzo de 1926, similar a la ley de $1908^{5}$ en su liberalismo en el sentido de que la entrada a México continuó siendo básicamente libre, sin imponer cuotas. La nueva Ley menciona sin embargo la posibilidad de introducir restricciones en el futuro. ${ }^{6} \mathrm{La}$ única limitación que se impuso entonces era que los inmigrantes mayores de 25 años tenían que saber leer y escribir.

La ley de 1926 modificó el marco institucional correspondiente, con lo cual el Servicio de Migración de la Secretaría de Gobernación pasó a ser Departamento de Migración. Este se organizaba por oficinas dedicadas tanto a los asuntos inmigratorios como emigratorios, que se distribuían por todo el país con una preponderancia en el norte donde se acumulaba casi la mitad de ellas por la alta tasa de salidas. El sur, con tráfico muy reducido en ambos sentidos, recibió poca atención, con solo 4 oficinas, mientras las zonas del Golfo y del Pacífico -áreas principalmente de entrada- tenían el 22\% y el 25\% de las oficinas respectivamente, pero aún así, solo juntas sobrepasaban el porcentaje de la zona prioritaria, la del norte. ${ }^{7}$

Gráfica 1: Distribución geográfica de las Oficinas del Departamento de Migración ${ }^{8}$

a) porcentajes

b) número de oficinas
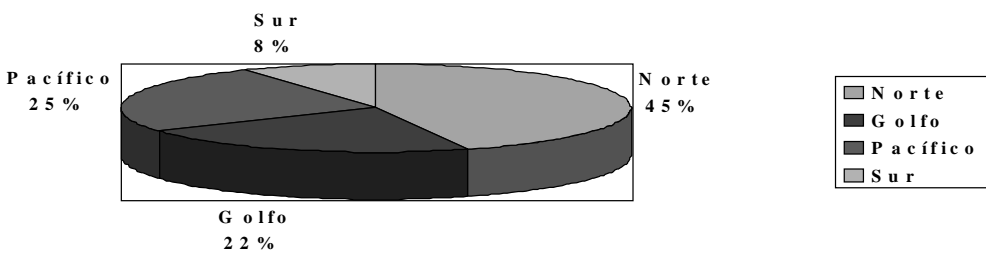

$\square$ sur

\begin{tabular}{|l|l|l|l|l|}
\hline Norte & Golfo & Pacífico & Sur & Total \\
\hline 26 & 13 & 15 & 4 & 58 \\
\hline
\end{tabular}

La ley de 1926 también impuso nuevas disposiciones sobre el registro y administración de los inmigrantes. Se puso énfasis especial en el seguimiento del movimiento migratorio, creándose la tarjeta individual de identificación, que contenía los siguientes rubros para datos':

- renglones oficiales: número de solicitud y de registro, autoridad y fecha de expedición, lugar y fecha de entrada al país, calidad migratoria, firmas del funcionario que expide la tarjeta y del interesado, más dos fotos de la persona en cuestión, una de frente y otra de perfil;

- media filiación del interesado, con los detalles del aspecto físico;

- datos complementarios: edad, fecha, lugar y país de nacimiento, nacionalidad actual, estado civil, ocupación, idioma nativo, otros idiomas, religión, raza, residencia y referencias mexicanas.

\footnotetext{
${ }^{5}$ La entrada de una persona solamente podía negarse por mala salud o mala conducta.

${ }^{6}$ Esto, como se observará, indudablemente sirvió como base para posteriores modificaciones.

${ }^{7}$ La preponderancia de las oficinas a lo largo de la frontera con los Estados Unidos es una clara indicación del orden de importancia otorgado tanto por el Departamento de Migración como por la propia ley: la prioridad de la emigración ante la inmigración.

${ }^{8}$ SRE IV-380-12, Andrés LANDA Y PIÑA, Estudio sobre el Servicio de Migración en México, 1931

${ }^{9}$ Desafortunadamente, en muchos casos no se llenaron todos los rubros, lo que sin duda es el problema más grave que el investigador tiene al procesar dichas tarjetas. Otra dificultad es la lectura de la información original, parcialmente por el estado de los papeles, pero más significativamente por la curiosa ortografía encontrada en ellas, que fue el resultado tanto del deseo de los propios inmigrantes de pasar las formalidades lo más pronto posible, como de la falta de conocimientos por parte de las autoridades mexicanas.
} 
A través de la ley de 1926 se sistematizó el registro de la entrada y salida tanto de nacionales como de extranjeros creándose el Registro Nacional de Extranjeros (RNE), se definieron oficialmente las diferentes calidades migratorias, y se decretó la compilación de datos estadísticos. Con el fin de cubrir por lo menos parcialmente los gastos derivados de esta reorganización, se introdujo el impuesto del inmigrante, aplicable en todos los casos, con la excepción de los estudiantes y, más tarde, de los asilados políticos. La mitad de este impuesto ingresaba directamente la Tesorería de la Federación y la otra parte al Departamento de Migración.

\begin{tabular}{|c|c|c|}
\hline $\begin{array}{l}\text { calidad } \\
\text { migratoria }^{11}\end{array}$ & $\begin{array}{l}\text { definición } \\
\text { Es el extranjero que }\end{array}$ & $\begin{array}{l}\text { Estancia } \\
\text { máxima }\end{array}$ \\
\hline no inmigrante & $\begin{array}{l}\text { ingresa temporalmente, } \\
\text { diferentes motivos }\end{array}$ & \\
\hline asilado político & $\begin{array}{l}\text { entra en el país para proteger su } \\
\text { libertad o su vida de persecuciones } \\
\text { en su país de origen }\end{array}$ & sin límite \\
\hline estudiante & $\begin{array}{l}\text { entra en el país para iniciar o } \\
\text { completar sus estudios }\end{array}$ & $\begin{array}{l}\text { la duración de los } \\
\text { estudios }\end{array}$ \\
\hline transmigrante & $\begin{array}{l}\text { cruza el territorio nacional para } \\
\text { dirigirse a otro país }\end{array}$ & 30 días \\
\hline turista & $\begin{array}{l}\text { entra al país exclusivamente por } \\
\text { motivos de recreo }\end{array}$ & 6 meses \\
\hline visitante & $\begin{array}{l}\text { puede dedicarse a actividades } \\
\text { remuneradas dentro del país }\end{array}$ & 6 meses \\
\hline visitante local & $\begin{array}{lllr}\text { permanece } & \text { en } & \text { los } & \text { puertos } \\
\text { marítimos, o en } & \text { ciudades } \\
\text { mexicanas de la frontera } & \end{array}$ & 3 días \\
\hline inmigrante & $\begin{array}{l}\text { entra en el país para radicarse en } \\
\text { él, con posibilidad de trabajar }\end{array}$ & $\begin{array}{l}\text { un año, } \\
\text { refrendable, máx. } \\
5 \text { años }\end{array}$ \\
\hline $\begin{array}{ll}\text { inmigrante } & - \\
\text { trabajador } & \end{array}$ & $\begin{array}{l}\text { entra en el país para dedicarse a un } \\
\text { trabajo físico }\end{array}$ & ibid \\
\hline $\begin{array}{l}\text { inmigrante rentista } \\
\text { o pensionista }\end{array}$ & $\begin{array}{l}\text { vive de un ingreso fijo proveniente } \\
\text { del extranjero (rentas, bonos } \\
\text { estatales, pensión) }\end{array}$ & ibid \\
\hline $\begin{array}{l}\text { inmigrante } \\
\text { inversionista }\end{array}$ & $\begin{array}{l}\text { entra en el país para invertir su } \\
\text { capital en la economía nacional }\end{array}$ & ibid \\
\hline inmigrante familiar & $\begin{array}{l}\text { entra en el país para vivir bajo la } \\
\text { dependencia económica de un } \\
\text { familiar inmigrante, inmigrado o } \\
\text { mexicano }\end{array}$ & ibid \\
\hline inmigrado & $\begin{array}{l}\text { una vez transcurrido el tiempo } \\
\text { límite en cualquiera de las } \\
\text { calidades de inmigrante, solicita y } \\
\text { obtiene su radicación definitiva en } \\
\text { el país }\end{array}$ & sin límite \\
\hline
\end{tabular}

\footnotetext{
${ }^{10}$ Carlos A.ECHÁNOVE TRUJILlo, Manual del Extranjero, México, Editorial Porrúa, sin fecha, 18-20

${ }^{11}$ Para dar una perspectiva más amplia, el cuadro-resumen incluye también las categorías añadidas más tarde, como asilado político.
} 
Otro aspecto nuevo de esta ley fue que incorpora por vez primera a los turistas como categoría migratoria, como parte de un empeño por aumentar el número de los mismos, por significar un ingreso económico para el país. Para ello se otorgaban varias concesiones que significaron la simplificación de la entrada y del papeleo correspondiente. ${ }^{12}$ No es de extrañar por lo tanto que muchos de los húngaros inmigrantes llegaron originalmente como turistas y solamente después, ya estando en México, solicitaron el cambio de categoría a la de inmigrante.

En las condiciones que dieron luz a la segunda ley de migración en México convergían razones inmigratorias y emigratorias. En tal virtud, la ley naturalmente contenía legislación tanto sobre inmigración como sobre emigración. Este último tema queda sin embargo fuera del marco de este estudio, y por lo tanto no se detalla.

\section{Restricciones}

La inmigración decreció en la segunda mitad de los años veinte y en los treinta debido tanto a la gran crisis económica mundial como a las limitaciones impuestas por México, como alcances o enmiendas a la Ley de 1926. Estas restricciones se iniciaron solamente contra los inmigrantestrabajadores, considerados como competencia indeseable para los trabajadores nacionales. La primera fue introducida el 15 de julio de 1927, seguida por limitaciones más estrictas en abril de $1929 .{ }^{13}$ Sin embargo, en otoño del mismo año se permitió nuevamente la entrada de los inmigrantestrabajadores, ${ }^{14}$ si bien esto fue pronto seguido por nuevas limitaciones. Así, la segunda parte de los años veinte se puede caracterizar por un empeño por parte del gobierno mexicano para suprimir o por lo menos limitar las entradas de trabajadores extranjeros. Sin embargo, esto no resultó en una línea política consistente, ya que, como se observa, las restricciones aparecían y desaparecían, lo que puso tanto a los consulados como a las compañías navieras en una situación bastante difícil. ${ }^{15}$ Para los treinta, el empeoramiento de la crisis financiera mundial y de la situación económica interna del país causaron en parte que la política mexicana de inmigración se volviera más estricta, más consistente y más selectiva. Mientras en la década anterior las restricciones solamente afectaron a los inmigrantestrabajadores, el campo de las limitaciones se amplió en los años treinta e incluyó varias ocupaciones ${ }^{16}$ y nacionalidades.

\footnotetext{
12 Para los turistas se diseñó por ejemplo una tarjeta especial, la F-11.

${ }^{13}$ SRE-AHD IV-394-41, 1931

14 ibid, acuerdo confidencial de la Secretaría de Gobernación

${ }^{15}$ SRE-AHD IV-135-50, 1929

${ }^{16}$ médicos, profesores, eclesiásticos
} 
Tabla 2 Restricciones a nacionalidades

\begin{tabular}{|c|c|c|c|}
\hline año & mes & restricción a nacionalidades & fuente \\
\hline 1930 & 1 & $\begin{array}{l}\text { se prohibe la entrada de sirios, libaneses, } \\
\text { armenios, palestinos, árabes, chinos, turcos, } \\
\text { rusos y polacos, con la excepción de casos } \\
\text { de reunión con familiares ya naturalizados } \\
\text { mexicanos }\end{array}$ & $\begin{array}{l}\text { Pasaporte a la } \\
\text { esperanza p. } 72-73\end{array}$ \\
\hline 1930 & 8 & $\begin{array}{l}\text { prohibición absoluta de la inmigración } \\
\text { polaca }^{17}\end{array}$ & $\begin{array}{l}\text { El convenio ilusorio, } \\
\text { p.85 }\end{array}$ \\
\hline 1931 & 5 & $\begin{array}{l}\text { prohibición absoluta de la entrada de los } \\
\text { gitanos }{ }^{18}\end{array}$ & $\begin{array}{l}\text { Los extranjeros en } \\
\text { México y los } \\
\text { mexicanos en el } \\
\text { extranjero Vol III } \\
\text { p.36 }\end{array}$ \\
\hline 1933 & 10 & $\begin{array}{l}\text { prohibición de la entrada de las razas } \\
\text { negra, amarilla19, malaya e "indúe" (sic) } \\
\text { "por razones étnicas", así como de } \\
\text { nacionales de las Repúblicas Soviéticas } \\
\text { Socialistas "por razones políticas" y de los } \\
\text { gitanos "por sus malas costumbres". Se } \\
\text { declara como poco deseables }{ }^{20}: \text { a los } \\
\text { polacos, lituanos, checos, eslovacos, sirios, } \\
\text { libaneses, palestinos, armenios, árabes y } \\
\text { turcos porque "constituyen un motivo de } \\
\text { competencia desventajosa para nuestros } \\
\text { nacionales." }\end{array}$ & $\begin{array}{l}\text { Circular } 250 \text {, de la } \\
\text { Sría. de Gobernación, } \\
\text { Depto. de Migración }\end{array}$ \\
\hline 1934 & 1 & $\begin{array}{l}\text { adiciones a la circular 250: prohibición de } \\
\text { la entrada de las razas australiana, } \\
\text { mongólica e "indoeuropea oriental" (sic). } \\
\text { Se incluye entre los poco deseables, "por la } \\
\text { clase de actividades a que se dedican dentro } \\
\text { del país", a los "estuanos" (sic), letones, } \\
\text { búlgaros, rumanos, persas, yugoslavos y } \\
\text { griegos. Asimismo, por "ser exóticos para } \\
\text { nuestra psicología", a los albaneses, } \\
\text { afganos, abisinios, argelinos, egipcios y } \\
\text { marroquíes. Prohibición de la inmigración } \\
\text { judía. }\end{array}$ & $\begin{array}{l}\text { Circular } 157 \text {, de la } \\
\text { Sría. de Gobernación, } \\
\text { Depto. de Migración }\end{array}$ \\
\hline
\end{tabular}

\footnotetext{
${ }^{17}$ La mayoría de los inmigrantes polacos eran judíos y la porción más grande de la comunidad judía radicada en México provenía de Polonia.

${ }^{18}$ Lo cual podría haber afectado el ingreso de los húngaros (identificados en México con los gitanos), lo cual afortunadamente no se dio, ya que la limitación no menciona nacionalidad específica.

${ }^{19}$ Excepto los japoneses.

${ }^{20}$ Las nacionalidades así consideradas necesitaban la precalificación de la Secretaría de Gobernación antes de arribar.
} 


\section{Xenofobia}

Tanto las limitaciones impuestas en base a la nacionalidad, como las demás razones dadas para justificarlas, implican un tinte de racismo, o por lo menos prejuicios de algún tipo. El razonamiento para la supresión de la inmigración polaca fue por ejemplo que los polacos o bien se dedicaban al comercio ambulante o agitaban a los trabajadores. ${ }^{21}$ La crisis económica por desgracia hizo brotar los sentimientos xenófobos en México, lo que se manifestó en una presión para suprimir totalmente la inmigración y en acciones contra los extranjeros radicados en territorio nacional, de los cuales los más afectados fueron los chinos. En varios estados se establecieron comités anti-chinos y había campañas organizadas, muchas veces violentas, contra ellos.

El creciente nacionalismo (en el que no faltó una dosis de xenofobia) y el empeoramiento de la crisis económica fueron los principales motivos para una nueva legislación migratoria: la Ley de Migración de 1930 y su Reglamento (1932). Estos nuevos documentos reforzaron las restricciones y además subrayaron la necesidad de contar con un registro más estricto.

Todos los extranjeros radicados o que en el futuro radiquen en el país, quedan obligados a manifestar ante las autoridades correspondientes, todas las circunstancias de su identificación personal, dentro de los treinta días siguientes a la publicación de esta ley en los lugares de residencia, o dentro de seis meses de su entrada al país. ${ }^{22}$

En efecto, esta fue la época en que por ejemplo la mayoría de los inmigrantes húngaros se presentaron ante las autoridades mexicanas. Sin embargo esto fue un registro a veces años, incluso décadas posterior a su arribo, lo que significa que varios rubros de las tarjetas de identificación no son procesables, porque todo el mundo menciona ya el español como idioma hablado y, en lo referente a su estado civil, declara el actual, no el del momento de su llegada. Por desgracia, posiblemente con el fin de evitar posibles complicaciones, los inmigrantes tendieron a actualizar también los datos referentes a sus orígenes. La Monarquía Austro-Húngara ya no existía, por lo que, en la gran mayoría de los casos, los interesados preferían declarar sus lugares de nacimiento con el país actualizado, aunque en la realidad éste no existiera como tal en el momento de su nacimiento. Y así se dan casos en que alguna persona declaró por ejemplo haber nacido en 1902 en Checoslovaquia -país que fue creado en 1918- con lo cual se le hizo también conveniente anotar como lengua materna el checoslovaco, idioma inexistente en la realidad. Este y otros ejemplos, como el del declarante nacido en Yugoslavia y hablante de yugoslavo, parecieron lógicos a ojos del administrador mexicano, ignorante de las condiciones históricas y de los sucesos políticos y geográficos en Europa Central, y los datos quedaron asentados así en los registros.

Para poder llegar a una conclusión es conveniente dividir la época estudiada en dos períodos. El primero, hasta 1926, se caracterizó por un número creciente de entradas a México, producido principalmente por el sistema de cuotas introducido en los Estados Unidos. La legislación mexicana en esta etapa desempeñó un papel más bien pasivo, al no introducir cambios sustantivos y así mantener la ley de migración de 1908 vigente, lo cual significó entrada libre. Esta actitud hizo posibles los ingresos al país, si bien sin facilitarlos necesariamente. El segundo período, a partir de 1926, se caracteriza por menos entradas, a pesar de que había un número cada vez más alto de gente que quería emigrar de su país de origen, especialmente en los años treinta. Tal reducción fue el resultado en parte de la falta de recursos económicos de los inmigrantes en potencia, pero mucho más significativamente de la política mexicana de inmigración, impulsada a controlarla y restringirla, en virtud del alto desempleo y en general por el empeoramiento de la crisis económica nacional e internacional. En total se puede decir que en la primera mitad de los años veinte, la política mexicana de inmigración, no logró sustancialmente alterar el flujo de las llegadas, a pesar de algunos esfuerzos hechos por incrementarlas. Desde 1926, dicha política ya se puede considerar tanto la causa como el resultado de los movimientos inmigratorios, si bien haciendo la aclaración de que en ambos casos, causa y

\footnotetext{
${ }^{21}$ Gloria CARREÑO y Celia ZACK DE ZUKERMAN, El convenio ilusorio. Refugiados polacos de guerra en México (1943-47), México, [s.n.] 1998, 85

${ }^{22}$ Ley de Migración de 1930, capítulo XVI
} 
resultado, no en el sentido de promover y facilitar las entradas sino, al contrario, al organizarlas, reglamentarlas y restringirlas.

\section{Bibliografía:}

\section{Fuentes}

SRE-AHD

IV-135-2, 1929

IV-135-50, 1929

IV-380-12, 1931

IV-394-41, 1931

IV-395-9, 1931

Leyes de Migración de 1908, 1926 y 1930

Carlos A. ECHÁNOVE TRUJILLO, Manual del Extranjero, México, Editorial Porrúa, sin fecha

ARAUJO, VELILLA, y GARAU (ed.): Prontuario del Extranjero en México: cómo adquirir la nacionalidad mexicana; recopilación de la leyes vigentes sobre nacionalidad y naturalización, pasaportes y migración, con anotaciones prácticas y comentarios jurídicos sobre las mismas, México, Editora Nacional, 1950

\section{Bibliografía}

Sergio CAMPOSORTEGA CRUZ, Análisis demográfico de las corrientes migratorias a México desde finales del siglo XIX, in: María Elena OTA MISHIMA (ed.), Destino México. Un estudio de las migraciones internacionales a México, siglos XIX y XX, México, El Colegio de México 1997, $23-54$

Gloria CARREÑO, Pasaporte a la esperanza, in: Alicia GOJMAN DE BACKAL (ed.): Generaciones judías en México. La Kehilá Ashkenazi, 1922-1992, Tomo I, México, Comunidad Ashkenazí de México 1993

Gloria CARREÑO y Celia ZACK DE ZUKERMAN, El convenio ilusorio. Refugiados polacos de guerra en México (1943-47), México, [s.n.]1998

Moisés GONZÁLEZ NAVARRO, Los extranjeros en México y los mexicanos en el extranjero, México, El Colegio de México 1994

Gerardo HIDALGO URIBE, Inmigración de rentistas y pensionistas extranjeros. (Tesis de licenciado en derecho), México, UNAM,1965 